BIS WORKING PAPERS

No 94 - November 2000

\title{
CORPORATE HEDGING: THE IMPACT OF FINANCIAL DERIVATIVES ON THE BROAD CREDIT CHANNEL OF MONETARY POLICY
}

by

Ingo Fender

BANK FOR INTERNATIONAL SETTLEMENTS

Monetary and Economic Department

Basel, Switzerland 
BIS Working Papers are written by members of the Monetary and Economic Department of the Bank for International Settlements, and from time to time by other economists, and are published by the Bank. The papers are on subjects of topical interest and are technical in character. The views expressed in them are those of their authors and not necessarily the views of the BIS.

Copies of publications are available from:

Bank for International Settlements

Information, Press \& Library Services

CH-4002 Basel, Switzerland

Fax: +41 61 / 2809100 and +4161/2808100

This publication is available on the BIS website (www.bis.org).

(C) Bank for International Settlements 2000.

All rights reserved. Brief excerpts may be reproduced or translated provided the source is stated. 
BIS WORKING PAPERS

No 94 - November 2000

\title{
CORPORATE HEDGING: THE IMPACT OF FINANCIAL DERIVATIVES ON THE BROAD CREDIT CHANNEL OF MONETARY POLICY
}

\begin{abstract}
This complementary paper to Froot, Scharfstein, and Stein (1993) seeks to explore some of the corporate finance foundations of monetary economics. In particular, we investigate the impact of corporate risk management strategies on the monetary transmission mechanism. We employ a simple model of a financial accelerator (synonymously: a broad credit channel of monetary policy transmission) to argue that information asymmetries - which are at the heart of these models of the transmission mechanism - create incentives for corporate hedging programmes, that is, cash flow management. These policies, in turn, diminish the impact of monetary policy measures, which is reduced to the pure cost-of-capital effect.
\end{abstract}

Keywords: Corporate Finance, Monetary Transmission, Risk Management

JEL Classification: E44, E52, G31, G32

* I wish to thank Claudio Borio, Dietrich Domanski, Gabriele Galati, Roy Gardner, Jürgen von Hagen, Kenneth Kletzer, Manfred J M Neumann and Chris Waller as well as seminar participants at the Bank for International Settlements, the ZEI - Summer School on International Macroeconomics 1999 and at ZEI, University of Bonn for helpful comments and discussions. Any remaining errors and omissions are, of course, my own. 



\section{Contents}

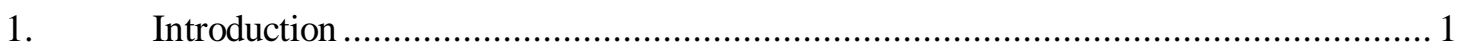

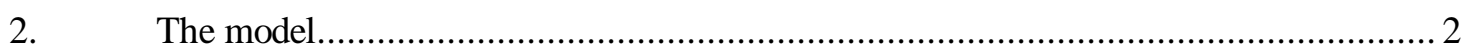

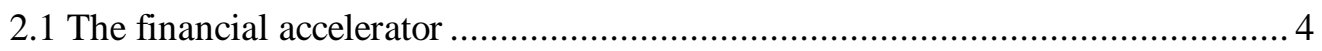

2.2 Period 2: The firm's investment decision........................................................... 5

2.3 Financial contracting under asymmetric information ....................................... 6

3. Derivatives, risk management, and monetary transmission ................................. 9

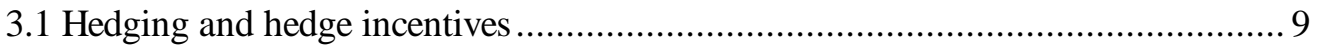

3.2 Period 1: The risk management decision ......................................................... 10

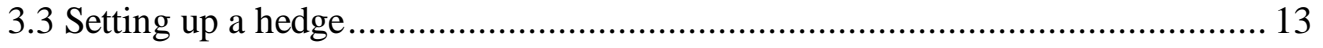

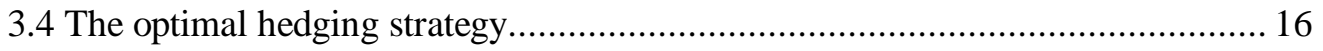

3.5 Monetary transmission and optimal hedging ................................................ 18

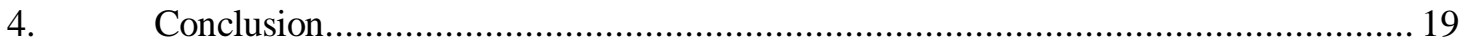

Annex A: Derivation of the optimal hedging strategy …...................................... 22

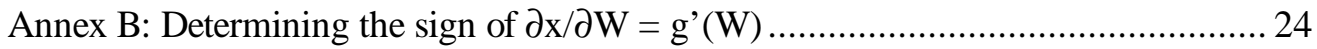





\section{Introduction}

The use of derivative instruments in corporate risk management has grown rapidly in recent years, caused partly by financial deregulation and partly by the success of the financial industry in designing a great variety of OTC and exchange-traded contracts. The overall scale of interest rate hedging policies implemented by non-financial firms seems to be substantial. The 1995 BIS survey on global derivatives markets reports a global gross market value of OTC interest rate contracts equal to US\$ 647 billion as of end-March 1995, while the notional amount outstanding in OTC and exchange-based markets for interest rate contracts was about US\$ 36 trillion. The latest BIS survey reports gross market values of about US\$ 1.4 trillion for OTC interest rate derivatives as of end-June 1998 and US\$ 61 trillion of notional amounts outstanding in the combined markets for interest rate derivatives. With $14.7 \%$ of the gross market values and $11.5 \%$ of the respective notional amounts falling to non-financial customers, this suggests that a maximum of one seventh of the interest rate derivatives outstanding at that time were potentially held for corporate hedging purposes. ${ }^{1}$

Derivatives enable their users to separate, value and transfer market risks. Risks are securitised and thus gain fungibility, which, in turn, allows the unbundling and repackaging of market risks embodied in underlying assets. The use of derivatives, therefore, enhances the possibilities for active corporate risk management, which is likely to have an impact on macroeconomic and monetary policy issues. A series of recent studies has taken a look at the possible impact of derivatives on monetary policy (among others: BIS (1994), Deutsche Bundesbank (1994), Issing and Bischofberger (1996) and Vrolijk (1997)). ${ }^{2}$ All of these studies speculate on the directions of change induced by derivatives' use and provide a broad overview of the financial system emerging from these changes. However, they fail to provide a theoretical analysis to support their ideas.

In this paper, we explore the corporate finance foundations of monetary transmission to understand how derivatives may affect monetary policy. Specifically, we follow the recent literature on the so-called "credit view" of monetary transmission. ${ }^{3}$ By emphasising a combination of market imperfections, such as informational frictions, and portfolio balance effects, this theory suggests that the state of a firm's balance sheet has implications for its ability to obtain external finance. Policy-induced interest rate changes will, therefore, not only work through the traditional interest rate effect, but will also be

\footnotetext{
1 See BIS (1999) and BIS (1996).

2 See von Hagen and Fender (1998) for a recent survey.

3 See, among others, BIS (1995), Cecchetti (1995), Gertler and Gilchrist (1993) and Ramey (1993).
} 
reinforced by balance sheet effects. The existence of informational frictions thereby creates a separate channel for policy transmission. By virtue of this separate channel, seemingly small changes in interest rates can have a large impact on real variables. This effect has been termed the "financial accelerator" (FA) or, focusing on monetary transmission, the "broad credit channel". 4

The informational asymmetries which are at the heart of these models of the monetary transmission mechanism create incentives for corporate risk management strategies based on interest rate derivatives. Hence, "broad credit channel" effects may be minimised, thereby reducing the impact of interest rate changes to the pure cost-of-capital effect. This suggests that financial derivatives are likely to have quite a strong impact on this specific transmission channel. Our study thus contrasts with the analysis of Romer and Romer (1993), who argue that: "[...] it is difficult to see how recent financial market innovations could have significantly affected this component of the transmission mechanism [ie the financial accelerator or broad credit channel]."

The paper is organised as follows. Section 2 presents a simple two-period model of firm investment behaviour generating a financial accelerator. Section 3 extends the model to allow for corporate risk management using interest rate derivatives. The model is then analysed following Froot et al (1993). We show that the underlying agency problem creates incentives for corporate hedging and derive the optimal hedging strategy. We conclude by drawing out the implications of our analysis for monetary policy transmission in a world with corporate risk management.

\section{The model}

We employ a simple, partial equilibrium model of firm investment behaviour adapted from Gertler and Hubbard (1988). ${ }^{6}$ The model is of a two-period nature and financial contracts are - as far as possible motivated from first principles. It employs asymmetric information in the credit markets, introduces interest rate risk and allows for corporate risk management using financial derivatives.

The firm enters the first period, which extends from $(t-1)$ to $t$, with an endowment of $e$. The firm actually wants to set up an investment project which requires financing at point $t$. The output yielded in the production process is then sold at time $(t+1)$. We assume that the investment project requires an

4

The terminology used with regard to the "credit view" of monetary policy is rather confusing and not clear-cut. Our analysis focuses on the so-called "broad credit channel" (Oliner and Rudebusch, 1996). The terms (broad) credit channel, financial accelerator, and balance sheet channel are used synonymously and without regard for the "bank lending channel" of monetary policy transmission.

5 Romer and Romer (1993), p 2, our italics.

6 See also Hubbard (1995), Bernanke et al (1996), and Hubbard (1997). 
up-front investment of $q<e$ at time $(t-1)$. The firm is therefore able to finance the required amount without turning to the credit market. The amount $(e-q)$ is saved and earns a known, risk-free interest rate of $r_{t-1}$. Figure 1 summarises the time structure of the model.

\section{Figure 1: Time structure of the model}

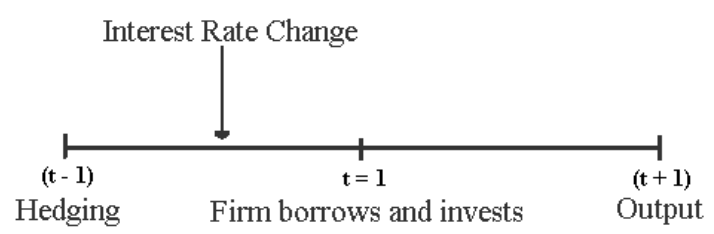

We assume that the up-front investment $q$ generates an illiquid asset $V$ at time $t$ which is a necessary input into the production process. Hence, we can think of the start-up investment as the cost of the acquisition of the production technology. The illiquid asset has a known price of $\gamma$ at $(t+1)$. We assume that the asset is not used up during the production process. The specific rate of depreciation is hence equal to zero. Given that the firm pledges the illiquid asset $V$, a fully collateralised loan to be entered into by the respective firm will therefore generate an amount of $\beta_{t} * \gamma * V$ at time $t$, where $\beta_{t}=\left(1+r_{t}\right)^{-1}$ equals the discount factor. The firm's cash flow at time $t$ is given by:

$$
W_{t}=\bar{w}+\gamma \cdot \beta_{t}, \text { with } \bar{w}=\left(1+r_{t-1}\right) \cdot(e-q) \text { and } V=1 \text {. }
$$

The firm's cash flow will therefore be interest rate sensitive, with the parameter $\gamma$ measuring the correlation between cash flow and the interest rate. We assume $\beta_{t}$ to be stochastic. Hence, the firm might decide to hedge the interest rate exposure of its cash flow by entering into derivatives contracts. Dealing with exposures to price or interest rate risks generally involves the creation of an offsetting position to the very risk to be hedged. Given that a firm's cash flow is lowered by an increase in interest rates, the firm might deal with the pre-hedge exposure to interest rate risk by taking an opposite position. The new exposure will gain value when interest rates rise and will thus offset the pre-hedge exposure created by the firm's cash flow. Depending on the actual derivatives contracts used by the firm, such a risk management strategy can fully insulate firm cash flow from changes in interest rates.

With the hedging decision being taken and after the realisation of the interest rate shock, the firm enters the second period, which extends from time $t$ to $(t+1)$. At this point, the firm needs to borrow additional funds in order to start the planned project. However, the production technology is risky with regard to productivity and, due to asymmetric information, exhibits a financial accelerator. 


\subsection{The financial accelerator}

The concept of the financial accelerator derives from informational asymmetries in the credit markets, which drive a wedge between the costs of external and internal finance. In particular, the higher cost of external finance reflects the agency costs of lending under asymmetric information. In such a situation, internally generated funds enable firms to reduce their demand for costly external finance. Hence, a fall in a borrower's net worth or cash flow raises the demand for external finance and subsequently reduces investment. Given that negative shocks affect cash flow individually, the effect of an initial shock to the economy may be amplified. Small shocks might therefore create large cycles, hence the term "financial accelerator". A contractionary monetary policy shock now reduces investment spending through the traditional cost-of-capital effect and, given that changes in interest rates affect corporate cash flows, ${ }^{7}$ lowers a firm's cash flow and its ability to borrow. Consequently, monetary policy impulses are reinforced by cash flow effects.

In the early literature, the Modigliani-Miller (1958) theorem states that financial structure is irrelevant to corporate investment decisions. More recent research, however, has questioned the assumption of perfect substitutability of external and internal funds by pointing to the existence of capital market imperfections. The most common argument posits that asymmetric information and problems of contract enforcement lead to the emergence of agency costs, thereby driving a wedge between the cost of external and internal finance. As outside investors require a premium for unobservable or uncontractable risks, external finance becomes more costly than internal finance. ${ }^{8}$

Other examples of a theoretical link between balance sheet positions and investment appear, among others, in Bernanke and Gertler (1990) and Calomiris and Hubbard (1990). Both papers predict that borrowers" investment decisions will be "excessively sensitive" to current cash flow: A rise (fall) in cash flow strengthens (weakens) the firm's balance sheet and thus lowers (increases) the cost of capital. It is, hence, possible to rationalise income accelerator effects on investment. Fazzari et al (1988) provide empirical support for these various propositions. They conduct a time series and cross-sectional analysis of a broad class of firms. Their main result is that investment is significantly more sensitive to current firm cash flow than a frictionless model would predict.

This view of the monetary transmission mechanism is supported by the empirical studies of, among others, Gertler and Gilchrist (1994), Oliner and Rudebusch (1996) and Bernanke et al (1996). They

7 In our setup, rising interest rates will lower the net worth of businesses by changing the present value of the firms' illiquid assets. This affects the firm's ability to obtain fully collateralised loans. Higher interest rates could, however, also affect cash flow through increased interest payments on existing floating rate or short-term debt. See Mishkin (1996) and Bernanke and Gertler (1995) for details.

8 See Myers and Majluf (1984) and Stiglitz and Weiss (1981) for early models on asymmetric information. 
focus on the differential behaviour of small and large firms and find that monetary policy shocks appear to affect the growth and investment of small manufacturing firms more than that of large manufacturers. Monetary policy actions have, therefore, a much stronger impact on small firms than on large firms, which seems to provide evidence in favour of an important credit channel for monetary policy which operates beyond the confines of the banking sector.

\subsection{Period 2: The firm's investment decision}

The firm utilises a production technology $y_{t+1}=f\left(x_{t}, c_{t}\right)$, generating an output $y_{t+1}$ by using of the two inputs $x_{t}$ and $c_{t}$. Output y is being sold at time $(t+1)$ and we assume that both inputs are entirely used up in the production process. Prices are fixed. The production technology is risky. The two possible states, "good" and "bad", are realised after the investment decision is made and the random realisation of the productivity parameter is assumed to be idiosyncratic. We assume that the stochastic nature of the production process is influenced by the firm's decision on input $c$. Namely, the firm is able to increase the probability of state "good" by use of a sufficient amount of input $c$. Suppose, however, that expenditures on input $c$ are unobservable by outside investors and creditors, thus introducing asymmetric information to the model. Given this assumption of unobservability, the firm 's manager may be tempted to cheat, ie to divert resources. In particular: ${ }^{9}$

$$
y_{t+1}=\left\{\begin{array}{cll}
f\left(x_{t}\right), & \text { with } \pi^{g} & \text { for } c_{t} \geq v x_{t} \\
\alpha \cdot f\left(x_{t}\right), & \text { with } \pi^{b} & \text { for } c_{t} \geq v x_{t} \\
\alpha \cdot \tau \cdot f\left(x_{t}\right), & & \text { for } c_{t}<v x_{t}
\end{array}\right.
$$

where $\pi^{i}$ denotes the probability for the realisation of state $i=g$ or $i=b$, satisfying the additivity condition $\pi^{g}=\left(1-\pi^{b}\right)$. The parameters $\alpha$ and $v$ are restricted to $0<\alpha<1$ and $v>0$, respectively. Parameter $\tau$ is assumed to take the value $\tau=0$ or $\tau=1$, depending on the particular firm. Firms in our model are, thus, heterogeneous with regard to $\tau$ and we may think of the economy as divided into two sectors. One of the sectors, made up by firms with $\tau=1$, will be subject to financial frictions relating to asymmetric information. The other sector, however, operates in a Modigliani-Miller setting. Each firm's production technology is assumed to be twice continuously differentiable, strictly increasing, and strictly concave.

It satisfies:

$$
f(0)=0 ; \quad f^{\prime}(x)>0 ; \quad f^{\prime}(0)=\infty ; \quad f^{\prime}(\infty)=0 ; \quad f^{\prime \prime}(x)<0 .
$$

\footnotetext{
9 See Gertler and Hubbard (1988) and Hubbard (1995).
} 
It is obvious that the manager will either use $c=v x$ units of input $c$ or none at all. We follow Hubbard (1995) and assume $\left(\pi^{g}+\alpha \pi^{b}\right) /(1+v)>\alpha$. This parameter restriction makes sure that the expected gain in output, net of additional input costs, is positive for $c=v x$. The decision-maker is risk-neutral and maximises the present value of expected net cash flows. At point $t=1$, he solves:

$$
\max _{x} \Pi_{1}+\beta_{1} E\left[\Pi_{2}\right]
$$

where

$$
\Pi_{1}=W_{1}-(1+v) x_{1}+b_{1}
$$

and

$$
E\left[\Pi_{2}\right]=f\left(x_{1}\right)\left(\pi^{g}+\alpha \pi^{b}\right)-\left(1+r_{1}\right) b_{1} .
$$

Net cash flows are denoted $\Pi_{t=1}$ and $\Pi_{t+1=2}$, with $W_{t=1}$ being the firm's gross cash flow at time $t$. Borrowing at time $t=1$ is $b_{1}$ and $\beta_{1}=1 /\left(1+r_{1}\right)$ denotes the firm's discount factor, where $r_{1}$ is the riskfree interest rate. Assuming $\tau=0$, the Modigliani-Miller (MM) theorem applies. Hence, there are no informational imperfections and the manager chooses optimal investment $x_{1} *$ to satisfy the first-order condition (FOC) of the maximisation problem (3):

$$
\beta_{1} \cdot f^{\prime}\left(x_{1}\right)\left(\pi^{g}+\alpha \pi^{b}\right)=(1+v) .
$$

Given equation (4), monetary transmission will work in a pretty straightforward manner. An increase in the gross market rate $\left(1+r_{t}\right)$ reduces the discount factor $\beta_{t}$ and, hence, investment demand:

$$
\frac{\partial x_{t}}{\partial \beta_{t}}=-\frac{f^{\prime}\left(x_{t}\right)\left(\pi^{g}+\alpha \pi^{b}\right)}{\beta_{t} \cdot f^{\prime \prime}\left(x_{t}\right)\left(\pi^{g}+\alpha \pi^{b}\right)}>0 .
$$

This is the traditional user-cost-of-capital channel of monetary transmission.

\subsection{Financial contracting under asymmetric information}

Under asymmetric information, $\tau=1$, things are quite different. ${ }^{10}$ Given that lenders cannot perfectly observe the firm's allocation of funds between $x$ and $c$, the manager may be tempted to divert resources to the capital markets, investing them at the riskless rate $r_{t=1}$. The resulting agency problem is, of course, recognised by possible creditors and will thus influence the way debt contracts are written. ${ }^{11}$

10 The assumption that only a particular group of firms faces problems of asymmetric information and, hence, costly external financing is chosen for convenience. However, it is more plausible to assume that firms switch between "constrained" and "unconstrained" regimes depending upon shifts in investment opportunities and the availability of internal and external financing. See Hubbard (1997).

11 Note that the precise form of the informational friction does not change the underlying problem. Bernanke and Gertler (1990), for example, introduce private information with regard to the expected return of investment projects, while Calomiris and Hubbard (1990) model private information with regard to project risk. The basic story, however, remains unchanged. 
Optimal financial contracts will therefore take account of the decision makers' incentive problem, to make sure that the incentive to divert resources is eliminated. This, in turn, will lead to an investment demand, which is lower than the desired demand under MM conditions and hence called "underinvestment". ${ }^{12}$ Suppose that, given $W_{1}<x_{1} *$, the firm's manager enters a contract with a riskneutral, competitive financial intermediary. The amount borrowed at $t=1$ is defined as:

$$
b_{t}=x_{t}(1+v)-W_{t}>0 \text {. }
$$

Investments $x_{t}(1+v)$ in our model are thus partially financed internally, using the firm's cash flow, as well as externally, by borrowing money. The contractual agreement between lender and borrower is chosen to maximise the firm's expected net cash flows.

To ensure enforceability of the contract, its specifications have to be designed in a way sufficient to satisfy the zero profit condition of the financial intermediary (7) as well as an incentive compatibility constraint (8):

$$
\begin{aligned}
& \pi^{g} R_{t+1}^{g}+\pi^{b} R_{t+1}^{b}=\left(1+r_{t}\right)\left((1+v) x_{t}-W_{t}\right), \\
& f\left(x_{t}\right)\left(\pi^{g}+\alpha \pi^{b}\right)-\pi^{g} R_{t+1}^{g}-\pi^{b} R_{t+1}^{b} \geq\left(\alpha f\left(x_{t}\right)-R_{t+1}^{b}\right)+\left(1+r_{t}\right) v x_{t} .
\end{aligned}
$$

Condition (8) makes sure that honest behaviour in the sense of an investment of all available resources dominates the case of cheating, where the entrepreneur diverts resources from the investment project for an (unobserved) investment in riskless assets. Given a realisation of state $b$, however, the manager can credibly commit to a payment of the bad outcome only. Hence, in addition to (8) and (7), the following limited liability constraint has to be satisfied:

$$
R_{t+1}^{b} \leq \alpha f\left(x_{t}\right)
$$

The contract specifications have to be chosen in a way sufficient to satisfy the conditions stated above. The creditor therefore defines repayments $R^{g}$ and $R^{b}$ in accordance with conditions (7) to (9). Following Gertler and Hubbard, we assume the limited liability constraint (9) to be strictly binding. Combination of the conditions yields:

$$
\beta_{t} \cdot f\left(x_{t}\right)\left(\pi^{g}+\alpha \pi^{b}\right)-\left((1+2 v) x_{t}-W_{t}\right) \geq 0 \text {. }
$$

The entrepreneur will now maximise equation (3) subject to the conditions (6) and (10). The resulting FOC for this problem is given by equation (4). The optimal (desired) investment demand at $t=1, x_{t}^{*}$, is identical to optimal investment under MM assumptions.

12 A variant of this underinvestment problem was first identified by Myers (1977). 
There are two general solutions to the above contracting problem. In the first case, internal funds, ie cash flow, will be high enough to make sure that (10) is non-binding. Investment demand, therefore, will adjust to the optimal level $x_{t}{ }^{*}$, just like under MM conditions. In such a case, the internally generated share of funds is high enough to reduce the underlying incentive problem in a way that is sufficient to support the optimal volume of investment. Financing and investment decisions will thus be independent. The situation is very different, however, if (10) binds with equality. In this case, financing and investment decisions will be mutually interdependent. As long as the firm's cash flow is too low, (10) will hold with equality and investment will be restricted to a level lower than the MM optimum. It follows from $x_{t}^{*}>x_{t}$ that:

$$
f^{\prime}\left(x_{t}^{*}\right)<f^{\prime}\left(x_{t}\right)
$$

This is the phenomenon of "underinvestment" resulting from informational frictions in the credit markets. The extent of the underlying agency problem is measured by the following equation for the agency costs incurred:

$$
A \equiv \beta_{t} f^{\prime}\left(x_{t}\right)\left(\pi^{g}+\alpha \pi^{b}\right)-(1+v) .
$$

These costs will be positive, given the reduction in investment relative to the first-best level defined by the Modigliani-Miller case. Another way to think about the resulting agency costs is in terms of the spread between the (implicit) gross interest rate on loans and the riskless gross rate. ${ }^{13}$ The cost for uncollateralised external finance does, thus, exceed that for internal finance. The existence of asymmetric information drives a wedge between these two sources of financial funds. For a given gross interest rate and the optimal investment demand $x_{t}{ }^{*}$, the critical level for the firm's cash flow can be defined by:

$$
W_{t}^{*}=(1+2 v) x_{t}^{*}-f\left(x_{t}^{*}\right)\left(\pi^{g}+\alpha \pi^{b}\right) \cdot \beta_{t} .
$$

For any cash flow lower than the critical value $W^{*}$, equation (10) will bind with equality. The relative values of $\beta_{\mathrm{t}}$ and $W_{t}$ thus determine the firm's feasible volume of investment. That is, the firm's investment demand is now implicitly defined by equation (10) and may be rewritten in the following functional form:

$$
x_{t}^{d}=\left\{\begin{array}{cc}
g\left(\beta_{t}\right), & \text { for } W_{t}>W_{t} * \\
g\left(\beta_{t}, W_{t}\right), & \text { for } W_{t} \leq W_{t} *
\end{array} .\right.
$$

The partial derivatives of (14) follow from equation (10) and can be shown to equal:

13 To see this, multiply equation $(12)$ by $(1+r) /(1+v)$. 


$$
\begin{aligned}
& g^{\prime}\left(W_{t}\right)=\left((1+2 v)-f^{\prime}\left(x_{t}\right)\left(\pi^{g}+\alpha \pi^{b}\right) \cdot \beta_{t}\right)^{-1}>0, \\
& g^{\prime \prime}\left(W_{t}\right)=f^{\prime \prime}\left(x_{t}\right)\left(\pi^{g}+\alpha \pi^{b}\right) \cdot \beta_{t} \cdot g^{\prime}\left(W_{t}\right)^{3}<0,
\end{aligned}
$$

and

$$
\partial g^{\prime}\left(W_{t}\right) / \partial \beta_{t}=g^{\prime}\left(W_{t}\right)^{2} \cdot A^{\prime}\left(\beta_{t}\right)
$$

For firms that are low on cash flow, ie with $W_{t} \leq W_{t}^{*}$, investment demand is a concave function of the resources available internally. A reduction of the firm's cash flow reduces the share of own funds devoted to the investment project, thereby increasing the underlying agency problem. As a result, feasible investment will fall. Equation (10) thus creates a specific influence of the firm's cash flow on investment demand. The scale of investment plans is determined not only by traditional factors, namely the rule of investing up to the point where marginal cost is equal to marginal benefits, but also by the resources available internally.

The simple framework of a financial accelerator has strong implications for the functioning of the monetary transmission mechanism. Given that firm investment is an increasing function of internally generated funds and with, as in our setup, cash flow and market interest rates being negatively correlated, a credit channel effect arises. An increase in interest rates will affect investment spending not only by changing the cost of capital. In addition, cash flow will decrease and therefore enhance the impact of a given change in interest rates.

This is what Oliner and Rudebusch (1996) call the "broad credit channel" and what is otherwise termed the "balance sheet channel" of monetary transmission. In such a model, monetary policy, that is a change in interest rates, exhibits a direct as well as an indirect effect. The direct effect of a change in the cost of capital is thus reinforced by an indirect effect which operates through the interest rates' impact on cash flow. It is this effect which is at the heart of the "balance sheet channel" of monetary transmission. Given that a firm's cash flow declines when interest rates rise, the decline in cash flow will enhance the depressing impact of interest rates on corporate investment spending. ${ }^{14}$

\section{Derivatives, risk management and monetary transmission}

\subsection{Hedging and hedge incentives}

In the following sections, we ask whether and how the use of financial derivatives will influence the credit channel of monetary policy transmission. Following the analysis of risk management (Stulz

14 See, again, Mishkin (1996) and Bernanke and Gertler (1995) for details. 
(1984), Smith and Stulz (1985) and Froot et al (1993)), informational asymmetries create incentives for corporate risk management strategies based on the firm's cash flow. Specifically, we extend the basic framework of Froot et al (1993) to the case of variable interest rates.

It is a fundamental insight that, under uncertainty, risk-averse decision-makers will prefer stable income and consumption streams to highly variable ones. Under the assumption of risk aversion, a decisionmaker's utility will therefore be higher, given that he is able to stabilise income or consumption streams. Hedging, by enabling agents to increase expected utility via consumption smoothing, is hence a well defined strategy for risk-averse decision-makers. The argument is less clear-cut for hedge decisions taken by corporations. In a Modigliani-Miller world, there is no room for hedging. The answer to the question for the incentives of corporate hedging does, therefore, lie in a departure from the ModiglianiMiller theorem.

Smith and Stulz (1985), for instance, base their explanation of risk-averse firm behaviour on three fundamental reasons: convex tax schedules, managerial risk aversion and bankruptcy costs. First, less variable pre-tax values of a firm imply higher after-tax values than do more variable pre-tax values, given the progressive structure of the corporate tax code. Hedging, then, helps to raise after-tax firm values by reducing the variability of the pre-tax value.

Second, if management compensation is tied to a firm's performance, managers will act in a risk-averse manner in order to maintain their compensation. The third argument claims that hedging helps to lower the probability that a firm will go bankrupt. In the presence of positive bankruptcy costs, hedging will thus benefit stockholders and creditors by reducing the expected future costs incurred in case of bankruptcy.

Credit market imperfections based on asymmetric information produce yet another rationale for corporate risk management (Froot et al, 1993). The incentive to hedge is created by variability in a firm's cash flow, for it is cash flow which influences the cost of external finance. This is why, under asymmetric information, we expect firms to engage in risk management strategies aimed at the stabilisation of their cash flow.

\subsection{Period 1: The risk management decision}

We will now turn to the role of corporate risk management under the conditions of a financial accelerator. To do this, we will work our way backwards through the model. Given the risk of a change in interest rates, a firm's cash flow will be variable at time $t=1$. To deal with this, we introduce derivatives markets and allow the firm to acquire derivatives contracts at time $(t-1)=0$. 
We can now examine whether the model implies the existence of hedge incentives and how corporate risk management is to be designed in order to maximise a firm's discounted net cash flows. Feasible investment in our model depends on interest rates and cash flow, which in turn depends on interest rates. Firms are therefore able to stabilise cash flows using interest rate derivatives, for this is one of the very characteristics of these contracts.

We assume the interest rate at time $t=1$ to be stochastic. The discount rate $\beta_{\mathrm{t}}=1 /\left(1+r_{t}\right)$ is now defined as follows:

$$
\beta_{t}=\beta_{t-1}+\chi, \text { where } E\left[\beta_{t}\right]=\beta_{t-1}
$$

and $\quad \beta_{t+i}=\frac{1}{1+r_{t+i}}$ for $t=1$ and $i=-1,0$.

The $\chi$ denotes a random variable with expected value $E(\chi)=0$ and known variance $\operatorname{VAR}(\chi)=\sigma_{\chi}^{2}$, incorporating the risk of a change in interest rates. Any positive realisation of the random variable $\chi$ implies falling interest rates. With the interest rate shock being realised, cash flow at $t=1$ is given as follows:

$$
W_{1}=w+\gamma \chi, \text { with } w=\bar{w}+\gamma \beta_{0} .
$$

The interest rate shock $\chi$ is defined by the following probability distribution:

$$
G(\chi):\left[\chi^{\min }, \chi^{\max }\right] \rightarrow[0,1]
$$

where $\quad \chi^{\max }=-\chi^{\min } ; \chi^{\max }>0$ and $\beta_{t=0}+\chi^{\min }>0$.

We follow Froot et al (1993) and restrict the interest rate shock to be symmetrically distributed around zero. This restriction simplifies the analysis considerably and enables the firm to engineer a costless, ie self-financing, hedge. ${ }^{15}$ The firm's decision-maker is now assumed to maximise the discounted, expected net cash flows under the condition of interest rate uncertainty.

At time $(t-1)=0$ he solves the following, modified version of problem (3):

$$
\max \beta_{0} E\left[\Pi_{1}\right]+\beta_{0} E\left[\beta_{1} \Pi_{2}\right]
$$

subject to the following conditions:

$$
\Pi_{1}=W_{1}-(1+v) x_{1}+b_{1} \geq 0
$$

15 A symmetric distribution of the interest rate shock implies a neutral stance of the central bank. Central banks are, of course, able to change the shape of the distribution. However, policy measures like this are not considered in this paper. 


$$
\beta_{1} \Pi_{2}=\beta_{1} \cdot y_{2}-b_{1} \text {, and }
$$

$$
\beta_{1} \cdot f\left(x_{1}\right)\left(\pi^{g}+\alpha \pi^{b}\right)-\left((1+2 v) x_{1}-W_{1}\right) \geq 0
$$

Equation (19) defines the combined constraints (7) through (9) and equals equation (10) for $t=1$. The expression $y_{2}$ is defined by (2). For $E\left[W_{1}\right]<E\left[W_{1} *\right]$, the firm is expected to be credit constrained in the sense of our basic model outlined above. We assume that $\beta_{0}=1$ and that (17) always holds with equality. The decision-maker will now follow Froot et al (1993) to solve the firm's optimisation problem backwards, starting with the determination of expected cash flow. Given $E\left[W_{1}\right]<E\left[W_{1}^{*}\right]$, the firm's feasible investment depends on expected cash flow and the manager's incentive constraint. We can now use (19) to determine the volume of feasible investment implied by the firm's expectations on cash flow and interest rates:

$$
E\left[\beta_{1}\right] f\left(\hat{x}_{1}\right)\left(\pi^{g}+\alpha \pi^{b}\right)-(1+2 v) \hat{x}_{1}+E\left[W_{1}\right]=0 \rightarrow \hat{x}_{1} .
$$

In addition, we apply the following restriction:

$$
\frac{(1+2 v)}{f^{\prime}\left(\hat{x}_{1}\right)\left(\pi^{g}+\alpha \pi^{b}\right)}-1>\chi^{\max } \text { and } 1-\frac{(1+v)}{f^{\prime}\left(\hat{x}_{1}\right)\left(\pi^{g}+\alpha \pi^{b}\right)}>-\chi^{\min }=\chi^{\max }
$$

The parameter restriction given above serves to provide a reliable financial accelerator effect, while retaining the symmetric structure of the probability distribution. It limits $\chi^{\max }$ and assures that the agency costs incurred by the firm as well as the impact of a change in cash flow on feasible investment do not change their sign for any possible interest rate shock. By virtue of this restriction, every firm that expects to be credit constrained in the sense of our model will actually be credit constrained after the shock has been realised.

Under these conditions, the optimisation problem boils down to the decision on the firm's risk management strategy. At time $t=0$, the firm will decide whether it is optimal to engage in risk management. The problem defined by equations (16) to (19) is reduced to the maximisation of the term $E\left[\beta_{1} \Pi_{2}\right]$, which is now rewritten as:

$$
E\left[P\left(\chi, W_{1}(\chi)\right)\right]=E\left[\beta_{1} f\left(\hat{x}_{1}\right) \cdot\left(\pi^{g}+\alpha \pi^{b}\right)-(1+v) \cdot \hat{x}_{1}+W_{1}(\chi)\right] .
$$

Following Smith and Stulz (1985) and Froot et al (1993), cash flow hedging will increase firm value, given that the manager's decision problem is concave in the risky variable to be hedged, ie cash flow. Their result is thus an analogy to the general case of a risk-averse, utility-maximising decision-maker under uncertainty. Given concavity of the firm's decision problem, represented by equation (20), our risk-neutral firm will act in a risk-averse manner. Our analysis concentrates on interest rate risk and disregards all other possible sources of uncertainty in the economy. The basic logic of the model, 
however, would remain unchanged for other as well as multiple sources of price risk. In what follows, we assume that the available instruments allow for complete stabilisation of firm cash flow. In addition, we abstract from the possible costs incurred by setting up a hedge. ${ }^{16}$ This implies that expected cash flow remains unchanged.

Positive as well as negative realisations of the random variable will, given the setup presented above, lead to fluctuations in a firm's feasible investment. An incentive to hedge the variations in cash flow will exist when the firms' decision problem is shown to be concave in cash flow. Doing this for equation (20) yields: ${ }^{17}$

$$
E\left[P_{W}\right]=E\left[1+A \cdot g^{\prime}\left(W_{1}\right)\right]>0
$$

and

$$
E\left[P_{W W}\right]=E\left[\beta_{1} f^{\prime \prime}\left(\hat{x}_{1}\right)\left(\pi^{g}+\alpha \pi^{b}\right) \cdot g^{\prime}\left(W_{1}\right)^{2} \cdot\left(1+A \cdot g^{\prime}\left(W_{1}\right)\right)\right]<0 .
$$

The agency costs implied by the underlying informational asymmetries are, again, denoted by $A$, which is now evaluated at the point of feasible investment (19'):

$$
A=A\left(\beta_{1}, \hat{x}_{1}\right) \equiv\left(\beta_{1} f^{\prime}\left(\hat{x}_{1}\right)\left(\pi^{g}+\alpha \pi^{b}\right)-(1+v)\right) .
$$

The signs of expression (21) and (22) are given by the positivity of agency costs $A$, the derivative of investment demand (14) and the assumption of $f^{\prime \prime}(x)<0$. Due to this, we find positivity of condition (21) and global negativity of condition (22), implying that hedging cash flow in $t=1$ will increase the expected present value of net cash flows. ${ }^{18}$ The concavity of the decision problem resembles the situation of a risk-averse expected utility maximiser and will thus make the risk-neutral, valuemaximising corporation behave $a$ s if it were a risk-averse investor.

\subsection{Setting up a hedge}

To set up a hedge, the firm requires information about the exposure to be hedged $\left(\Delta_{P}\right)$, ie the "pre-hedge exposure". Focusing on interest rate risk, the firm might calculate the exposure of its cash flow to changes in interest rates using the concept of modified duration. The duration of a portfolio is essentially a price elasticity, measuring the sensitivity of present value to a change in the discount rate, assuming a parallel shift of the term structure of interest rates. However, a measure like the duration

\footnotetext{
16 See Smith and Stulz (1985).

17 See Froot et al (1993). To simplify our notation, we denote first and second derivatives with $P_{W}$ and $P_{W W}$.

18 Expressions (21) and (22) are conditional on the assumption $E(W)<E\left(W^{*}\right)$. One of the implications of our model is that firms with high cash flows are not affected by FA effects and are hence risk-neutral.
} 
might be of little use in evaluating the interest rate sensitivity of a non-financial firm. Alternatively, one could measure the historical sensitivity of the company's cash flows to changes in interest rates and other variables by using a linear regression. The estimated regression coefficient on the interest rate variable will represent the average exposure of cash flow to interest rates in the past. The concept of exposure thus provides a single, comprehensive measure that summarises the sensitivity of the firm's cash flow to all the various ways in which interest rate changes can affect it.

A firm exposed to interest rate risk will seek to neutralise this exposure by creating an offsetting position $\left(\Delta_{H}\right)$. The objective is to manipulate the firm's exposure so that any adverse change $\Delta_{P}$ will be matched by an offsetting change in the value of the hedge position $\Delta_{H}$. The two positions add up to the following target exposure:

$$
\Delta_{W}=\Delta_{P}+z \cdot \Delta_{H} .
$$

The variable $z$ denotes the number of derivative contracts necessary to create the desired exposure $\Delta_{\mathrm{W}}$, $\Delta_{P}$ denotes the pre-hedge exposure of the firm's portfolio (cash flow) to the risk of a change in interest rates $\sigma_{\chi}$, and $\Delta_{H}$, finally, indicates the interest rate sensitivity of the value of the derivatives contract used. A hedger concerned about rising interest rates (negative realisations of $\chi$ for a firm with $\gamma>0$ ) would typically sell (go short on) interest rate futures. In doing so, he assumes the obligation to deliver certain fixed income instruments, ie bonds and similar contracts, in the future. If interest rates increase, prices for bonds and similar contracts decline, and the hedger delivers the necessary contracts or, alternatively, buys back the futures contract more cheaply. Because of this, profits from closing out such a hedge position can be used to at least partially offset the losses on the pre-hedge portfolio that have been created by rising interest rates.

In what follows, we will consider corporate risk management using interest rate options as well as (synthetic) forwards. In setting up a hedge, the firm effectively adds an additional position to the existing pre-hedge cash flow. We can represent this process by the following general framework:

$$
W_{1}=W(\chi)=w+\gamma \chi+\eta(\chi) .
$$

In this setup, the function $\eta(\chi)$ represents the hedge exposure of the firm, that is a position of derivatives contracts that generates cash flows in response to changes in interest rates (ie realisations of $\chi$ ). Due to the building block nature of option contracts, we can think of setting up the firm's hedge along the lines of the following example: ${ }^{19}$

$$
W_{1}=w+\gamma \chi+z_{p}\left[(k-\gamma \chi)^{+}-p_{0}\right]+z_{c}\left[c_{0}-(\gamma \chi-k)^{+}\right],
$$


where $(k-\gamma \chi)^{+}=\max \{0, \quad k-\gamma \chi\} ;(\gamma \chi-k)^{+}=\max \{0, \gamma \chi-k\}$.

In this example, the firm creates two separate positions of interest rate options that are added to the original cash flow. While exclusively based on non-linear contracts (options), the firm might generate either a linear or a non-linear strategy, depending on how the different parameters are chosen. In equation (24), $z_{p}$ defines the magnitude of a "put position". This exposure will gain value in case of rising interest rates, ie for negative realisations of the random variable $\chi$. The firm creates such an exposure by use of an "interest rate cap", where the "strike price" of the contract is defined by $k$. A mirroring "call position" $z_{c}$ is established by writing a "floor". With $E(\chi)=0$ and due to the assumption of a symmetric probability distribution, the downside risk of rising interest rates exactly equals the respective upside risk of falling rates. The firm can thus finance the purchase of caps by writing an appropriate number of floors. For simplicity, we assume the option premia $p_{0}$ and $c_{0}$ to be due for payment at the time of the option's expiration $t=1$. Defining $\theta=z_{p}$ and assuming $k=0$ as well as $p_{0}=$ $c_{0}$, we can now reformulate equation (24) as follows:

$$
W_{1}=w+\gamma(1-\theta) \chi+\left(z_{c}-z_{p}\right) \cdot\left[c_{0}-(\gamma \chi)^{+}\right] .
$$

Equation (24') highlights the difference between linear and non-linear hedging programmes. The parameter $\theta$ denotes the firm's (linear) hedge ratio, while $\left(z_{c}-z_{p}\right)$ determines the degree of non-linearity of the hedging strategy. Choosing $z_{p}=z_{c}$, the firm's hedging program will be linear, reducing the analysis to (synthetic) forwards. ${ }^{20}$ Under this assumption, a hedge ratio of $\theta=1$ implies that the original cash flow is fully insulated against interest rate shocks, while a value of $\theta=0$ is equivalent to a nohedge situation.

However, such a linear strategy does not necessarily create the first-best hedge of the firm's cash flow. ${ }^{21}$ This is easily shown using the graphical representation of the firm's hedging strategy provided below. Figure 2 shows desired investment resulting from the firm's optimisation problem and the supply of resources as a function of interest rates. As interest rates rise above the expected level, desired investment falls. However, both curves are downward-sloping and desired investment will not be feasible, because the firm's cash flow declines as well. The optimal hedging programme of the firm will rotate the supply-of-funds curve counterclockwise. Such a simple rotation can be generated using linear

19 See Broll and Wahl (1992) for a similar setup.

20 In a static world, one can identify a firm's risk management strategy by inspecting the type of instruments used. Firms employing forwards and swaps use linear strategies, while firms purchasing options usually use non-linear strategies. Tufano (1996) reports from a panel of gold producers that over the period 1990-93 three quarters of the firms managing risk used options for at least part of their programme.

21 See Froot (1995) for details. 
contracts like futures, forwards and swaps. By adding such a position that gains value in case of rising interest rates and loses value in the opposite case, the firm is able to add liquid resources in case of a declining supply of funds. This adds value to the firm itself, because it actually dislikes variations in cash flow due to the concavity of its decision problem. The optimal hedge-ratio $\theta^{*}$ corresponds to a situation where the supply-of-funds schedule perfectly matches the desired-investment curve. By rotating the supply-of-funds curve, the firm actually trades the upside risk of declining interest rates against the downside risk of rising rates. Due to the symmetry of our setup, such a strategy will be selffinancing.

Figure 2: The firm's hedging strategy

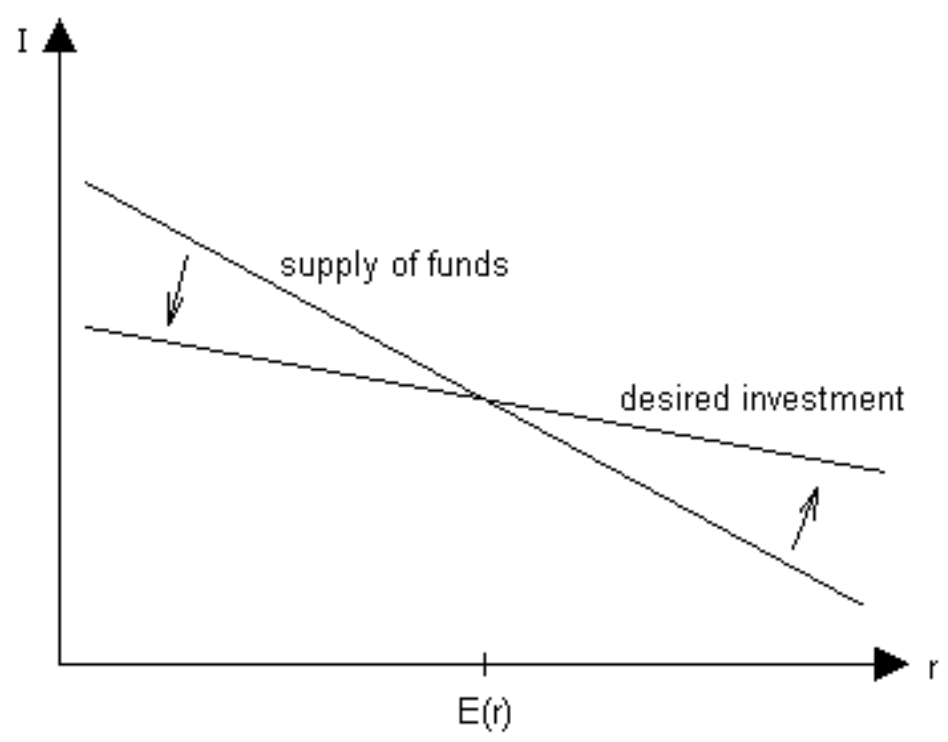

In some cases, however, a simple rotation of the supply-of-funds curve would not be enough to align the supply with the actual demand for funds. This is the case when at least one of the curves is not a straight line. In such a situation, the optimal hedge will no longer need simply to rotate the supply-offunds schedule, but rather to change the shape of the schedule as well. This will only be made possible by applying non-linear hedging strategies using options (Froot, 1995).

\subsection{The optimal hedging strategy}

The use of non-linear strategies effectively enables the firm to tailor a hedge on a state by state basis. Returning to the general setup of equation (23), this is reflected by $\eta(\chi)$. Under the assumption of 
complete options markets, the firm's risk management decision will now involve choosing a profile for cash flow across the different states of nature, $W_{t}^{*}=W^{*}(\chi)$, to maximise discounted net cash flow: ${ }^{22}$

$$
\max _{W(\chi)} \int_{-\infty}^{\infty} P(\chi, W(\chi)) \varphi(\chi) d \chi
$$

where $\varphi(\chi)$ denotes the density function of the random variable $\chi$. In addition, we impose the following "fair-pricing" constraint that makes sure that the firm's hedging strategy cannot change the expected value of cash flow:

$$
\int_{-\infty}^{\infty} W(\chi) \varphi(\chi) d \chi=w
$$

Equation (26) takes advantage of the symmetric distribution of the interest rate shock and can be interpreted as the zero profit condition of a risk-neutral derivatives dealer. It makes sure that the firm's hedge will be self-financing and that hedging cannot change the expected level of cash flow (Froot et al, 1993). The FOC for the optimisation problem defined by (25) subject to (26) is now given by:

$$
P_{W}=\lambda
$$

where $P_{W}$ is given as in expression (21) and where $\lambda$ defines the Lagrange multiplier on condition (26). As in Froot et al (1993), the FOC implicitly defines an optimal level of cash flow for every realisation of $\chi$. With $\lambda$ being a constant, the firm's optimal strategy requires the term $P_{W}$ to be stabilised over all states:

$$
P_{W \chi}=A_{\chi} \cdot\left(g^{\prime}(W)+A \cdot g^{\prime}(W)^{2}\right)=0
$$

This, in turn, requires:

$$
A_{\chi}=\left.A_{\chi}\right|_{\Delta W=0}+A_{W} \cdot W_{\chi}=0
$$

We thus obtain the optimal sensitivity of the firm's cash flow in each state:

$$
\frac{\partial W *(\chi)}{\partial \chi}=-\frac{\left.A_{\chi}\right|_{\Delta W=0}}{A_{W}},
$$

where $W^{*}(\chi)$ denotes the optimal level of cash flow for every realisation of $\chi \cdot{ }^{23}$ Equation (28) defines the first-best hedge of the firm, given that fairly priced options are available. The optimal strategy will

\footnotetext{
22 See Froot et al (1993), pp 1646-47.

23 See, again, Froot et al (1993) as well as the Annex for details.
} 
stabilise the agency costs induced by asymmetric information across all states of nature $\left(A_{\chi}=0\right)$, that is, over all interest rate shocks.

It is important to note that the firm will in general not stabilise cash flow perfectly. It might even choose to "overhedge", ie increase the volatility of cash flow, in order to stabilise agency costs. This is due to the fact that changes in interest rates may feed into agency costs either directly or indirectly, in other words via changes in cash flow. As apparent from equation (27), full stabilisation of cash flow $\left(W_{\chi}=0\right)$ will only be optimal when all other influences for changing interest rates are equal to zero.

Our result extends the findings of Froot et al (1993) in two important ways. First, we are able to show that, although more complicated to model, their framework of hedge incentives applies to interest rate risk as well. In addition, given that our approach rests on first principles, we are able to interpret the optimal hedge in terms of agency costs. It appears that the optimal strategy of the firm targets the level of agency costs generated by the underlying informational frictions. The optimal risk management strategy of the firm does not therefore generally involve complete insulation of cash flow from market risks, because this target will usually depart from the goal of agency cost stabilisation.

\subsection{Monetary transmission and optimal hedging}

Does corporate risk management change the effectiveness of monetary policy? The answer to this question has to take account of the two different effects monetary policy actions might have. Without hedging, an increase in interest rates under the conditions of a financial accelerator will work directly through interest rates as well as indirectly through the firm's cash flow. However, given that firms apply their optimal risk management strategy, they will try to stabilise agency costs or, to put it differently, the extent of "underinvestment" induced by the informational frictions in place. Recall that agency costs are defined by equation (12'). By inserting equation (4), we yield:

$$
A=\left(\beta_{1} f^{\prime}\left(\hat{x}_{1}\right)\left(\pi^{g}+\alpha \pi^{b}\right)-\beta_{1} f^{\prime}\left(x_{1}^{*}\right)\left(\pi^{g}+\alpha \pi^{b}\right)\right) .
$$

The second term on the right-hand side of (29) equals the first-order condition of the firm's optimisation problem under Modigliani-Miller assumptions and is, hence, constant. Any change in the interest rate, i.e. the discount factor $\beta_{1}$, is reflected by a change in the optimal level of investment. Agency costs or, more precisely, the derivative of $A$ with respect to the interest rate shock $\left(A_{\chi}\right)$ are, thus, a measure of monetary policy transmission relative to the standard cost-of-capital effect. The more $A_{\chi}$ deviates from zero, the more important credit channel effects are. It is obvious that, given that the firm applies its optimal hedge policy, there is no room for a sizeable credit channel. The optimal risk management strategy, as defined by equation (28), fully insulates agency costs from changes in the interest rate. The derivative $A_{\chi}$ is stabilised at a level of zero and the impact of monetary policy shocks on investment 
demand will be reduced to the pure cost-of-capital effect. This pure effect, however, should be rather small, as suggested by empirical evidence on the interest rate elasticity of investment demand. Nevertheless, it needs to be stressed that the implications drawn from the above analysis may look different in a general equilibrium framework, depending on the inter-sectoral redistribution of risk emerging from the implemented hedging programmes. The size of the effect, if any, thus remains an open question.

\section{Conclusions}

In this paper, we have combined a model of a broad credit channel for monetary transmission with a theory on corporate incentives for risk management. The goal of our analysis was to examine the theoretical relevance of the broad credit channel for monetary policy in a world with established derivatives markets and greatly improved possibilities to manage risks. We have shown that the very assumption at the heart of standard broad credit channel models of monetary transmission, namely the existence of asymmetric information in the credit markets, generates incentives to engage in corporate hedging strategies aimed at insulating the agency costs induced by asymmetric information from changes in interest rates. Our model thus indicates that, given that financial derivatives are available, firms subject to problems of asymmetric information should not be expected to accept their fate, that is, the effects of balance sheet channel transmission, like lemmings. Instead, they will implement corporate risk management strategies that are likely to significantly alter the sensitivity of the real economy to changes in interest rates.

The premise of the model developed above is that the use of financial derivatives allows companies to hedge against financial accelerator effects due to asymmetric information in the credit markets. When entering into derivatives contracts, companies are thus assumed to face information asymmetries to a lesser extent than they do in the credit markets. This assumption is based on the contractual nature of derivative instruments and the microstructure of their respective markets. The various institutional arrangements in place (marking-to-market, net cash settlement, margin requirements, reduced performance periods, notional underlyings) essentially reduce the credit risk exposure of the contract counterparty. This limits the impact of creditworthiness considerations and makes derivatives markets at least in principle - accessible to firms which would be unable to be active in other markets.

In the extreme case of perfectly self-financing hedge implementation and under the assumption of zero basis risk, optimal corporate risk management was actually shown to completely eliminate any broad credit channel effect of monetary policy. In doing so, corporate hedging will reduce monetary policy transmission to the pure cost-of-capital effect generated by the interest rate channel. Increased use of 
financial derivatives in corporate risk management will thus diminish any balance sheet channel effect of monetary policy (ie the impact of a given interest rate change on the real economy), just as innovations like certificates of deposit or regulatory changes have worked to reduce the impact of the bank lending channel. Given our results, there is no room for a sizeable credit channel in the presence of corporate risk management. Our model thus supplements the analysis of Thornton (1994). Whether this is for the good or the bad is, to some degree, an open question. On the one hand, monetary policy will be more costly because a given reaction of the real economy will demand a greater variation in interest rates under the new regime. On the other hand, policy shifts will lose their distributional aspects, which serves to reduce the burden imposed on the smaller, less mature and faster growing firms.

The assumptions of perfectly self-financing hedge implementation, zero hedge costs and zero basis risk as well as the static nature of the model clearly have to be regarded as rather extreme. ${ }^{24}$ However, the complete absence of the notion of corporate hedging in the conventional transmission literature implies that the various financial accelerator models presented in this literature implicitly assume the relevant hedge costs to be infinite. ${ }^{25}$ It may be tempting to argue that, with liquid derivatives markets actually existing since the mid-1970s, the assumption of zero - rather than infinite - hedge costs is the more appropriate one from the perspective of the late 1990s. Our model thus contrasts the extreme assumption present in the literature with another, arguably less extreme one. However, one has to keep in mind that the validity of the optimal hedge derived above relies on a number of simplifying assumptions. It is, hence, clearly to be regarded as a limiting case as well.

In the real world, problems of risk management implementation, relating to hedge costs (ie the costs of executing the necessary transactions, like commissions and other transaction costs, and the costs of monitoring a hedging programme) on the one hand and basis risk on the other, will most likely create corporate hedges that are necessarily imperfect and whose performance will be uncertain. Firms will thus not generally be able to perfectly insulate themselves from the impact of monetary policy measures via the broad credit channel. Because of imperfect hedging, credit channel effects, while still likely to be significantly reduced, will not be completely eliminated by corporate hedging. As a result, monetary policy will be increasingly unreliable when used to affect investment spending and real activity. While the impact of monetary policy shocks on investment and aggregate demand will generally be smaller in the presence of corporate hedging, rather than in a no-hedge situation, the size of this reduction will be uncertain. We should expect the extent of this impact to depend on hedge performance, which will vary over time. The effectiveness of monetary policy in terms of real effects will thus be uncertain as well.

24 See Mello and Parsons (2000) for a recent model of dynamic corporate risk management capturing the intertemporal effects of a firm's hedging programme. 
Although approaching from a different angle, our analysis also reinforces the line of reasoning in Arnold and de Vries (1999). These authors argue that many aspects of a country's financial structure are endogenous to the monetary policy regime in place and that the introduction of the euro and a unified monetary policy will actually serve to remove any national differences in the European monetary transmission mechanism. We would argue that, in the presence of corporate hedging, this is also true for any broad credit channel effect, as firms react to the existence of this specific transaction channel by implementing hedging strategies. This will endogenously remove a source of possible differential responses in the transmission of monetary policy actions in the euro area. ${ }^{26}$

25 See Neumann (1995) for a similar criticism relating to the size of transaction costs under the bank lending view.

26 Recent econometric evidence on euro area monetary transmission seems to support the idea of a declining importance of asymmetric effects among euro-11 countries, which is in line with our approach (see Siegfried, 1999). 


\section{Annexes}

\section{Annex A: Derivation of the optimal hedging strategy}

We assume that the firm's manager has to decide on the use of derivatives contracts for hedging purposes at time $t=0$. However, all contractual payments relating to the derivatives in question take place at time $t=1$. In order to identify his decision problem, the manager has to derive the firm's expected cash flows. The expected discount factor and the firm's expected cash flow are defined as:

(A.1) $E\left[\beta_{1}\right]=\beta_{0}=1$ and $E\left[W_{1}\right]=w$.

Knowing this, the manager can apply (4) to solve for the optimal investment level:

$$
E\left[\beta_{1}\right] f\left(x_{1} *\right)\left(\pi^{g}+\alpha \pi^{b}\right)=(1+v) \rightarrow x_{1} * .
$$

This, in turn, yields the critical cash flow (13):

$$
W_{1} *=(1+2 v) x_{1} *-E\left[\beta_{1}\right] f\left(x_{1} *\right)\left(\pi^{g}+\alpha \pi^{b}\right)=(1+2 v) x_{1} *-(1+v) .
$$

Given that $w<E\left[W^{*}\right]$, the manager will, hence, expect to be credit constrained in $t=1$. The volume of feasible investment implied by $E\left[W_{1}\right]=w$ and $E\left[\beta_{1}\right]$ is:

$$
f\left(x_{1}\right)\left(\pi^{g}+\alpha \pi^{b}\right)-(1+2 v) x_{1}+w=0 \rightarrow \hat{x}_{1} .
$$

Therefore, the manager solves the following problem:

$$
\max E\left[P\left(\chi, W_{1}\right)\right]=\int_{-\infty}^{\infty} P(\chi, W(\chi)) \varphi(\chi) d \chi
$$

subject to:

$$
\beta_{1} \cdot f\left(x_{1}\right)\left(\pi^{g}+\alpha \pi^{b}\right)-\left((1+2 v) x_{1}-W_{1}\right)=0,
$$

where $\quad E\left[P\left(\chi, W_{1}\right)\right]=E\left[\beta_{1} f\left(\hat{x}_{1}\right)\left(\pi^{g}+\alpha \pi^{b}\right)-(1+v) \hat{x}_{1}+W_{1}\right]$,

and $\quad W_{1}=w+\gamma(1-\theta) \chi+\eta(\chi)$.

The constraint (A.6) implies:

$$
x_{1}^{d}=\left\{\begin{array}{cc}
g\left(\beta_{1}\right), & \text { for } W_{1}>W_{1}^{*} \\
g\left(\beta_{1}, W_{1}\right), & \text { for } W_{1} \leq W_{1}^{*}
\end{array}\right.
$$


For firms that are low on cash flow, ie with $W_{t} \leq W_{t}^{*}$, investment demand is therefore a concave function of the resources available internally (at $t=1$ ):

$$
g^{\prime}\left(W_{t}\right)=\left((1+2 v)-f^{\prime}\left(x_{t}\right)\left(\pi^{g}+\alpha \pi^{b}\right) \cdot \beta_{t}\right)^{-1}>0
$$

and

$$
g^{\prime \prime}\left(W_{t}\right)=f^{\prime \prime}\left(x_{t}\right)\left(\pi^{g}+\alpha \pi^{b}\right) \cdot \beta_{t} \cdot g^{\prime}\left(W_{t}\right)^{3}<0 .
$$

The definition of $A$ and equation (A.8) require the following parameter restrictions in order to make sure that both terms are actually positive for any shock $\chi$ :

$$
\frac{(1+2 v)}{f^{\prime}\left(\hat{x}_{t}\right)\left(\pi^{g}+\alpha \pi^{b}\right)}-1>\chi^{\max } \text { and } 1-\frac{(1+v)}{f^{\prime}\left(\hat{x}_{t}\right)\left(\pi^{g}+\alpha \pi^{b}\right)}>-\chi^{\min }=\chi^{\max }
$$

The parameter restriction above serves to provide a reliable financial accelerator effect. It ensures that the agency costs incurred as well as the impact of a change in firm cash flow on feasible investment do not change their sign for any possible interest rate shock. Every firm that expects to be credit constrained in the sense of our model will therefore actually be credit constrained after the shock has been realised. The setup above yields the following FOC:

(A.10) $\quad P_{W}=1+A \cdot g^{\prime}(W)=\lambda$.

The optimal strategy requires the term $P_{W}$ to be stabilised over all states. We can now specify:

(A.11) $\quad P_{W \chi}=A_{\chi} \cdot g^{\prime}(W)+A \cdot \partial g^{\prime}(W) / \partial \chi=A_{\chi} \cdot g^{\prime}(W) \cdot\left(1+A \cdot g^{\prime}(W)\right)$,

where $\quad \partial g^{\prime}(W) / \partial \chi=\left((1+2 v)-f^{\prime}(x)\left(\pi^{g}+\alpha \pi^{b}\right) \cdot \beta\right)^{-2} \cdot A_{\chi}=A_{\chi} \cdot g^{\prime}(W)^{2}$.

It follows for the FOC:

$$
P_{W \chi}=A_{\chi} \cdot\left(g^{\prime}(W)+A \cdot g^{\prime}(W)^{2}\right) \stackrel{!}{=} 0
$$

and

$$
A_{\chi}=\left.A_{\chi}\right|_{\Delta W=0}+A_{W} \cdot W_{\chi} \stackrel{!}{=} 0 .
$$




\section{Annex B: Determining the sign of $\partial x / \partial W=g^{\prime}(W)$}

Equation (14) establishes a link between a firm's feasible investment at time $t=1$ and the resources available internally, ie the firm's gross cash flow $W_{t}$. The first derivative of equation (14) with respect to $W_{t}$ is given as follows:

$$
g^{\prime}\left(W_{t}\right)=\left((1+2 v)-f^{\prime}\left(x_{t}\right)\left(\pi^{g}+\alpha \pi^{b}\right) \cdot \beta_{1}\right)^{-1} .
$$

In order to show that this expression is actually positive, we follow Gertler and Hubbard (1988) and note that the incentive constraint is given as:

$$
\begin{array}{ll}
\text { (10) } & f\left(x_{t}\right)\left(\pi^{g}+\alpha \pi^{b}\right) \cdot \beta_{t}-(1+2 v) x_{t}+W_{t}=0 \\
\Rightarrow & (1+2 v)=f\left(x_{t}\right)\left(\pi^{g}+\alpha \pi^{b}\right) \cdot \beta_{t} / x_{t}+W_{t} / x_{t} .
\end{array}
$$

This implies the following relationship:

$$
(1+2 v)-f^{\prime}\left(x_{t}\right)\left(\pi^{g}+\alpha \pi^{b}\right) \beta_{t}=f\left(x_{t}\right)\left(\pi^{g}+\alpha \pi^{b}\right) \beta_{t} / x_{t}-f^{\prime}\left(x_{t}\right)\left(\pi^{g}+\alpha \pi^{b}\right) \beta_{t}+W_{t} / x_{t} .
$$

Our assumptions regarding the production technology (positive, diminishing returns) imply:

$$
f\left(x_{t}\right) / x_{t}>f^{\prime}\left(x_{t}\right)
$$

$\Rightarrow \quad\left(f\left(x_{t}\right)\left(\pi^{g}+\alpha \pi^{b}\right) \cdot \beta_{t} / x_{t}-f^{\prime}\left(x_{t}\right)\left(\pi^{g}+\alpha \pi^{b}\right) \cdot \beta_{t}\right)>0$

and $\quad\left((1+2 v)-f^{\prime}\left(x_{t}\right)\left(\pi^{g}+\alpha \pi^{b}\right) \cdot \beta_{1}\right)^{-1}>0$.

It follows that the impact of changes to a firm's cash flow on the volume of feasible investment is actually positive. Given the setup and the time structure of our model, that is, a negative impact of rising interest rates on the firm's cash flow, this establishes the financial accelerator. A change in the interest rate will therefore affect the firm's feasible investment by the usual cost-of-capital effect as well as, indirectly, through changes in cash flow. 


\section{References}

Arnold, I J M \& C G de Vries (1999): "Endogenous Financial Structure and the Transmission of ECB Policy”, mimeo, Rotterdam: Tinbergen Institute.

Bank for International Settlements (1994): "Macroeconomic and Monetary Policy Issues Raised by the Growth of Derivatives Markets (Hannoun Report)", Basel.

Bank for International Settlements (1995): "Financial Structure and the Monetary Policy Transmission Mechanism", Basel.

Bank for International Settlements (1996): "Central Bank Survey of Foreign Exchange and Derivatives Market Activity 1995", Basel.

Bank for International Settlements (1999): "Central Bank Survey of Foreign Exchange and Derivatives Market Activity 1998”, Basel.

Bernanke, B \& M Gertler (1990): "Financial Fragility and Economic Performance”. Quarterly Journal of Economics 105(1), pp 87-114.

Bernanke, B \& M Gertler (1995): "Inside the Black Box: The Credit Channel of Monetary Transmission". Journal of Economic Perspectives 9(4), pp 27-48.

Bernanke, B, M Gertler \& S Gilchrist (1996): "The Financial Accelerator and the Flight to Quality". Review of Economics and Statistics 78, pp 1-15.

Broll, U \& J Wahl (1992): "Hedging with Synthetics, Foreign Exchange Forwards, and the Export Decision". Journal of Futures Markets 12(5), pp 511-17.

Calomiris, C W \& R G Hubbard (1990): "Firm Heterogeneity, Internal Finance, and Credit Rationing". Economic Journal 100, pp 90-104.

Cecchetti, S G (1995): “Distinguishing Theories of the Monetary Transmission Mechanism”. Federal Reserve Bank of St. Louis Review, May/June, pp 83-97.

Deutsche Bundesbank (1994): "Geldpolitische Implikationen der zunehmenden Verwendung derivativer Finanzinstrumente". Monatsberichte, November, pp 41-57.

Fazzari, S M, R G Hubbard \& B C Petersen (1988): "Financing Constraints and Corporate Investment". Brookings Papers on Economic Activity 88, pp 141-95.

Froot, K A (1995): "Incentive Problems in Financial Contracting: Impacts on Corporate Financing, Investment, and Risk Management Policies". Crane, D B et al. (eds.): The Global Financial System: A Functional Perspective, Boston, pp 225-61.

Froot, K A, D S Scharfstein \& J C Stein (1993): "Risk Management: Coordinating Corporate Investment and Financing Policies". Journal of Finance 48, pp 1629-58.

Gertler, M \& S Gilchrist (1993): "The Role of Credit Market Imperfections in the Monetary Transmission Mechanism”. Scandinavian Journal of Economics 95(1), pp 43-64.

Gertler, M \& S Gilchrist (1994): "Monetary Policy, Business Cycles, and the Behavior of Small Manufacturing Firms”. Quarterly Journal of Economics 109, pp 309-40.

Gertler, M \& R G Hubbard (1988): "Financial Factors in Business Fluctuations". Federal Reserve Bank of Kansas City (ed.): Financial Market Volatility, pp 33-71.

Hubbard, R G (1995): "Is there a “Credit Channel” for Monetary Policy?” Federal Reserve Bank of St. Louis Review 77(3), pp 63-77. 
Hubbard, R G (1997): “Capital-Market Imperfections and Investment". NBER Working Paper No. 5996, Cambridge, MA: NBER.

Issing, O \& K Bischofberger (1996): "Derivate und Geldpolitik". Duwendag, D (ed.): Finanzmärkte, Finanzinnovationen und Geldpolitik, pp 111-37.

Mello, A S \& J E Parsons (2000): "Hedging and Liquidity". Review of Financial Studies 13(1), pp 127-53.

Mishkin, F (1996): “The Channels of Monetary Policy Transmission: Lessons for Monetary Policy". NBER Working Paper No. 5464, Cambridge, MA: NBER.

Modigliani, F \& M H Miller (1958): "The Cost of Capital, Corporate Finance, and the Theory of Investment". American Economic Review 48, pp 261-97.

Myers, S C (1977): "Determinants of Corporate Borrowing". Journal of Financial Economics 5, pp 147-76.

Myers, S C \& N Majluf (1984): “Corporate Financing and Investment Decisions When Firms Have Information That Investors Do Not Have”. Journal of Financial Economics 13, pp 187-221.

Neumann, M J M (1995): “What Do We Know about How Monetary Policy Affects the Economy?". Federal Reserve Bank of St. Louis Review 77(3), pp 138-42.

Oliner, S D \& G D Rudebusch (1996): “Is there a Broad Credit Channel for Monetary Policy?" Federal Reserve Bank of San Francisco Economic Review, 1996/1, pp 3-13.

Ramey, V (1993): "How Important is the Credit Channel in the Transmission of Monetary Policy?" Carnegie-Rochester Series on Public Policy 39, December, pp 1-45.

Romer, C \& D Romer (1993): "Credit Channel or Credit Actions? An Interpretation of the Postwar Transmission Mechanism”. NBER Working Paper No. 4485, Cambridge, MA: NBER.

Siegfried, N A (1999): “Monetary Transmission Mechanisms in Euroland". Working Paper Series in Quantitative Macroeconomics, Hamburg: Hamburg University.

Smith, C W \& R M Stulz (1985): “The Determinants of Firms' Hedging Policies". Journal of Financial and Quantitative Analysis 20(4), pp 391-405.

Stiglitz, J E \& A Weiss (1981): “Credit Rationing in Markets with Imperfect Information”. American Economic Review 71, pp 393-410.

Stulz, R M (1984): “Optimal Hedging Policies". Journal of Financial and Quantitative Analysis 19(2), pp 127-40.

Thornton, D L (1994): "Financial Innovation, Deregulation, and the "Credit View" of Monetary Policy”. Federal Reserve Bank of St. Louis Review 76(1), pp 31-49.

Tufano, P (1996): “Who Manages Risk? An Empirical Examination of Risk Management Practices in the Gold Mining Industry”. Journal of Finance 51(4), pp 1097-137.

von Hagen, J \& I Fender (1998): "Central Bank Policy in a More Perfect Financial System”. Open Economies Review 9, pp 493-531.

Vrolijk, C (1997): “Derivatives' Effect on Monetary Policy Transmission”. IMF Working Paper WP/97/121, International Monetary Fund, Washington DC. 


\section{Recent BIS Working Papers}

80

November 1999

81

November 1999

82

November 1999

83

January 2000

84

January 2000

85

January 2000

86

March 2000

87

May 2000

88

June 2000

89

August 2000

90

September 2000

91

October 2000

92

October 2000

93

October 2000
A note on alternative measures of real bond rates

Interbank interest rates and the risk premium

Sacrifice ratios and the conduct of monetary policy in conditions of low inflation

Switching from single to multiple bank lending relationships: determinants and implications

What have we learned from recent financial crises and policy responses?

A defence of the expectations theory as a model of US long-term interest rates

Information, liquidity and risk in the international interbank market: implicit guarantees and private credit market failure

Monetary policy in an estimated optimisation-based model with sticky prices and wages

Evidence on the response of US banks to changes in capital requirements

Forecast-based monetary policy

Bank capital regulation in contemporary banking theory: a review of the literature

Measuring potential vulnerabilities in emerging market economies

Recent initiatives to improve the regulation and supervision of private capital flows

Trading volumes, volatility and spreads in foreign exchange markets: evidence from emerging market countries
Palle S Andersen

Henri Pagès

Palle S Andersen and William L Wascher

Luísa A Farinha and João A C Santos

William R White

Gregory D Sutton

Henri Bernard and Joseph Bisignano

Jeffery D Amato and Thomas Laubach

Craig Furfine

Jeffery D Amato and Thomas Laubach

João A C Santos

John Hawkins and Marc Klau

William R White

Gabriele Galati 


ISSN 1020-0959 